\title{
Neuroinflammation impairs adaptive structural plasticity of dendritic spines in a preclinical model of Alzheimer's disease
}

\author{
Chengyu Zou ${ }^{1,2,3,4} \cdot$ Yuan Shi $^{1,2} \cdot$ Jasmin Ohli $^{2} \cdot$ Ulrich Schüller $^{2}$ • \\ Mario M. Dorostkar ${ }^{2} \cdot$ Jochen Herms $^{1,2,3}$
}

Received: 15 July 2015 / Revised: 27 November 2015 / Accepted: 16 December 2015 / Published online: 2 January 2016

(C) The Author(s) 2015. This article is published with open access at Springerlink.com

\begin{abstract}
To successfully treat Alzheimer's disease (AD), pathophysiological events in preclinical stages need to be identified. Preclinical AD refers to the stages that exhibit amyloid deposition in the brain but have normal cognitive function, which are replicated in young adult APPswe/ PS1deltaE9 (deltaE9) mice. By long-term in vivo twophoton microscopy, we demonstrate impaired adaptive spine plasticity in these transgenic mice illustrated by their failure to increase dendritic spine density and form novel neural connections when housed in enriched environment (EE). Decrease of amyloid plaques by reducing BACE1 activity restores the gain of spine density upon EE in deltaE9 mice, but not the remodeling of neural networks. On the other hand, anti-inflammatory treatment with pioglitazone or interleukin 1 receptor antagonist in deltaE9 mice successfully rescues the impairments in increasing spine density and remodeling of neural networks during EE. Our data suggest that neuroinflammation disrupts
\end{abstract}

Electronic supplementary material The online version of this article (doi:10.1007/s00401-015-1527-8) contains supplementary material, which is available to authorized users.

Jochen Herms

jochen.herms@med.uni-muenchen.de

1 Department for Translational Brain Research, German Center for Neurodegenerative Diseases (DZNE), Munich, Germany

2 Center for Neuropathology and Prion Research, Ludwig-Maximilians-University, Munich, Germany

3 Munich Cluster of Systems Neurology (SyNergy), Ludwig-Maximilians-University Munich, Schillerstraße 44, 80336 Munich, Germany

4 Graduate School of Systemic Neuroscience, Ludwig-Maximilians-University, Munich, Germany experience-dependent structural plasticity of dendritic spines in preclinical stages of AD.

Keywords Preclinical AD - APPswe/PS1deltaE9 mice · Dendritic spines · Structural plasticity $\cdot$ Neuroinflammation

\section{Introduction}

As the most prevalent cause of dementia, Alzheimer's disease (AD) is characterized by progressive cognitive deficits, amyloid plaques, neurofibrillary tangles (NFTs) and neuronal loss, yet it still lacks an effective cure at the present time [21, 40]. The failure to develop successful pharmacotherapy may, at least partially, be ascribed to the long pathophysiological process, which starts many years before the stage of symptomatic AD [43]. Therefore, much earlier intervention in the asymptomatic or preclinical stages may be required to successfully treat $\mathrm{AD}[35,45]$.

Preclinical AD has been recently defined as the stages when amyloid is being deposited in the brain, but before the onset of any cognitive impairment [44]. Subjects in the preclinical stages are at risk for future cognitive decline [51]. Indeed, the lag between the appearance of amyloid plaques and detectable impairment in cognition is more than a decade [37, 44]. Growing evidence supports the notion that amyloid deposition disrupts functional networks in the brain of cognitively normal elderly [17, 32, 42, 46]. To have a better chance of curing $\mathrm{AD}$, it is therefore crucial to identify pathophysiological events occurring in preclinical stages that precede dementia during the initial formation of amyloid deposits.

Transgenic mouse models are essential research tools for uncovering $\mathrm{AD}$ pathogenesis as well as validating new therapeutic approaches. To recapitulate AD pathology, 
transgenic mouse models carry familial AD gene mutations in the amyloid precursor protein (APP) and/or presenilins (PS) based on the amyloid hypothesis, which postulates an increased production or decreased removal of the APP proteolytic fragment, amyloid $\beta$-protein $(\mathrm{A} \beta)$, as the primary cause of AD [16]. The transgenes with APP/PS mutations in mouse models lead to the formation of amyloid plaques and subsequent memory loss, but without the development of NFTs and massive neuronal loss [2]. Although these mice fail to replicate all aspects of the disease, they seem to faithfully imitate pre-dementia stages of AD [1].

Among the APP transgenic mouse models, APPswe/ PS1deltaE9 (deltaE9) mice have been widely used. They express APP with the Swedish mutation together with mutant human PS1 with a deletion of exon 9 [23, 39]. Interestingly, in deltaE9 mice, amyloid deposition precedes typical cognitive impairments [22, 50]. Amyloid plaques start to emerge at the age of 4-5 months $[4,14]$, while the performance of 7-months-old deltaE9 mice is normal in most cognitive tests $[27,34,50]$. The temporal lag between the emergence of amyloid plaques and the onset of dementia consequently provides a critical period to study pathophysiological events related to preclinical AD.

In this study, we used long-term in vivo two-photon microscopy to elucidate the adaptive spine plasticity of deltaE9 mice at young adult age. Our data demonstrated that deltaE9 mice failed to increase spine density and establish novel neural connections when exposed to enriched environment (EE), which was caused by neuroinflammation.

\section{Materials and methods}

\section{Animals}

APPswe/PS1deltaE9 (deltaE9) mice [22] (Jackson Laboratory) were crossed with GPF-M mice [10] (Jackson Laboratory) to obtain double transgenic offspring, which were heterozygous for the corresponding genes (deltaE9 $+/-\times$ GFP +/-). GFP positive littermates without APP/ PS1 transgenes were used as controls (deltaE9 $-/-\times$ GFP $+/-)$. BACE1 knockout mice [5] were also purchased from Jackson Laboratory, and deltaE9 $+/-\times$ Bace1 $+/-\times$ GFP $+/-($ deltaE9/Bace $+/-)$ were generated by interbreeding. All transgenic mice were maintained on C57BL/6 background. Female mice at the age of 4-5 months were used. Mice were housed and bred in pathogen-free environment in the animal facility at the Centre for Neuropathology and Prion Research of the LudwigMaximilians-University Munich (LMU), with food and water provided ad libidum $\left(21 \pm 1{ }^{\circ} \mathrm{C}\right.$, at $12 / 12 \mathrm{~h}$ light/ dark cycle). All mice were housed either singly in standard cages $(30 \times 15 \times 20 \mathrm{~cm})$ or in groups in environmentally enriched (EE) cages $(80 \times 50 \times 40 \mathrm{~cm})$ equipped with platforms and variety of toys, which were relocated 3 times per week. Pioglitazone ( 350 ppm, Actos ${ }^{\mathrm{TM}}$ ) was supplemented into rodent chow. All protocols and procedures involving animals were approved and conducted in accordance with the regulations of LMU and the government of Upper Bavaria (Az. 55.2-1-54-2532-62-12).

\section{Cranial window implantation and in vivo two-photon imaging}

The detailed surgical procedure of cranial window implantation has been described previously $[13,20]$. In brief, mice were anesthetized by intraperitoneal injection of ketamine/ xylazine (120 and $10 \mathrm{mg} / \mathrm{kg}$, respectively). Subsequently, dexamethasone $(6 \mathrm{mg} / \mathrm{kg})$ was injected to prevent development of cerebral edema. A piece of skull above the somatosensory cortex was then removed carefully with a dental drill. The exposed brain was cleaned with sterile saline and covered with a round glass coverslip $(D=4 \mathrm{~mm})$. The margin between the glass and skull was sealed with dental cement. Post-surgical mice were subcutaneously injected with carprofen (Pfizer, $4 \mathrm{mg} / \mathrm{kg}$ ) and cefotaxime (Pharmore, $250 \mathrm{mg} / \mathrm{kg}$ ). Lentiviruses (LV) encoding IL-1 RA (LV vector was a gift from Dr. van Dam [49]) were intraparenchymally injected into the cortex before implanting the coverslip when specified. LV encoding GFP was used as a control for evaluating the efficiency of IL-1 RA expression. The injection of the LV (200 $\mathrm{nl}$ per time at a titer of $\sim 10^{8}$ infecting units per $\mathrm{ml}$ ) was performed at 4 different sites in the exposed area of brain at the depth of 700-800 $\mu \mathrm{m}$. After 4 weeks of recovery period, mice were imaged by using a LSM 7MP microscope (Zeiss) equipped with a $20 \times$ objective (NA 1.0; Zeiss). Mice were anesthetized with isoflurane ( $1 \%$ in $95 \% \mathrm{O}_{2}$ and $5 \% \mathrm{CO}_{2}$ ) and placed on a heating pad to keep the body temperature at $37{ }^{\circ} \mathrm{C}$. Apical dendrites originating from GFP-labeled layer $\mathrm{V}$ pyramidal neurons were imaged in consecutive sessions (once per week). The imaging session did not last more than $60 \mathrm{~min}$. The unique pattern of blood vessels was used to re-localize the imaged regions in subsequent imaging sessions. GFP was excited by a femtosecond laser (Spectra Physics) at the wavelength of $880 \mathrm{~nm}$. The intensity of laser and settings of data acquisition were kept constant during experiments. To ensure the dendrites were chosen in amyloid plaque-free regions, methoxy-X04 $(1 \mathrm{mg} / \mathrm{kg})$ was intraperitoneally injected $24 \mathrm{~h}$ before imaging in the first and last time points. Overview images were taken as $424 \times 424 \times 350 \mu \mathrm{m}^{3}(0.83 \mu \mathrm{m} /$ pixel $)$. From the central regions of these images, apical dendrites $(10-80 \mu \mathrm{m}$ in depth below the surface of brain) were chosen for analysis to make sure the distance between them and amyloid plaques was more than $100 \mu \mathrm{m}$. Higher resolution images 
$(0.138 \mu \mathrm{m} / \mathrm{pixel})$ were used for counting dendritic spines. For illustration purpose, maximal projection images were deconvolved (AutoQuantX3), with contrast and brightness adjusted.

\section{Spine analysis}

Dendritic spines were analyzed manually in ZEN 2011 (Zeiss) by scrolling through the images in z-stacks. As the limitations of resolution in Z-direction, only laterally protruding spines were counted, as only those could be identified with certainty. In consecutive sessions, a dendritic spine was determined as the same if its location did not change within a range of $0.5 \mu \mathrm{m}$ along the dendrite. Otherwise, spines that disappeared or emerged compared to the previous imaging session were defined as formed or eliminated, respectively. Spine formation and elimination were normalized into $100 \%$ based on the calculations from the first and second imaging points. The fate of preexisting spines was calculated as the fraction of dendritic spines in the first imaging session that remained stable during the imaging period. Similarly, the fate of new-gained spines was the fraction of formed spines in the first week of EE or matching week of SC that remained stable during the rest of imaging period, indicating how many gained spines incorporated into neural circuits. Transient spines were determined as spines that did not survive more than 1 week and referred to the stability of gained spines in a short-term period.

\section{Immunochemistry}

Following transcardial perfusion with phosphate-buffered saline (PBS) and $4 \%$ paraformaldehyde (PFA), mouse brains were cut into $65 \mu \mathrm{m}$ thick sections from the somatosensory cortex after being fixed in $4 \%$ PFA overnight. Antibodies against GFAP (Abcam 1:500), Iba1 (Wako 1:500) and beta-amyloid (4G8, BioLegend, 1:500) were used to detect activated astrocytes, microglial, and amyloid beta, respectively. Anti-rabbit Alexa 647 antibody (Invitrogen 1:1000) was used as the secondary antibody. To stain amyloid plaques, sections were incubated with $145 \mu \mathrm{m}$ methoxy-X04 in PBS for $30 \mathrm{~min}$ and then washed with PBS. After mounting on glass coverslips by fluorescence mounting medium (Dako), sections were imaged using LSM 780 confocal microscope (Zeiss). Glial activation, plaque load, or amyloid pathology was quantified as the area with positive staining relative to the cortex area after maximal projection of confocal stacks.

\section{Western blot}

$10 \%$ cortical tissues (w/v) were homogenized on ice in lysis buffer with protease inhibitors (Roche), followed by centrifugation at $500 \mathrm{rpm}$ for $1 \mathrm{~min}$. The supernatant was collected and protein concentrations were adjusted by the bicinchoninic acid assay to ensure the same amount of protein being loaded for each sample $(80 \mu \mathrm{g})$. Samples were mixed with SDS-containing sample buffers and incubated at $100{ }^{\circ} \mathrm{C}$ for $20 \mathrm{~min}$. After electrophoresed on $12 \%$ sample gel, proteins were transferred into polyvinylidene difluoride membrane (Millipore). The primary antibodies against IL-1 $\beta$ (Cell signaling), IL-1 RA (Thermo Scientific) and tubulin (Santa Cruz) were used at 1: 1000 concentrations for immunoblotting. Protein bands were quantified by ImageJ.

\section{Quantitative real-time PCR}

For gene expression analysis in brain tissue, RNA extraction was performed using TRIzol (Invitrogen). Random hexamer primers, oligo dTs and Superscript II reverse transcriptase (Invitrogen) was used for generation of cDNA. For quantitative real-time RT-PCR, the LightCycler480 system (Roche) and the corresponding SYBR Green detection format was used. Beta-2-microglobulin $(\beta 2 M)$ was used as a housekeeper. All analyses were conducted as triplicates. Primers for $\beta 2 M$ were designed using Primer3 software. Sequences for the primers were as follows: $\beta 2 M$ forward, $\quad 5^{\prime}$-TGTCTTTCAGCAAGGACTGG- ${ }^{\prime} ; \quad \beta 2 M$ reverse, $5^{\prime}$-GATGCTGCTTACATGTATCG- $3^{\prime} ; I L-1 \beta$ forward 5'-GGCTGGACTGTTTCTAATGC-3'; $I L-1 \beta$ reverse 5'-ATGGTTTCTTGTGACCCTGA-3' [55].

\section{Statistics}

For statistical analysis and comparison, GraphPad Prism 5 was used. In the longitudinal measurements of spine analysis, extra sum-of-squares $F$ test was used when data were fitted with a line using the nonlinear regression. Comparison among groups was performed using one-way ANOVA followed by Newman-Keuls post-test. Two-tailed Student $t$ test was used in comparison between two different groups. The numbers of mice were 4-6 per group for in vivo imaging. 8-12 dendrites were imaged in each mouse. The length of each dendrite was $25-35 \mu \mathrm{m}$ and the number of spines was normalized to the dendritic length. Data are presented as mean \pm SEM. $N$ refers to the number of mice; $p<0.05$ was defined as statistically significant $\left(* p<0.05,{ }^{* *} p<0.01\right)$.

\section{Results}

Adaptive structural plasticity of dendritic spines is impaired in deltaE9 mice at the age of 4-5 months

Replicating the preclinical stages of AD [1, 44], 4-5-monthold deltaE9 mice develop amyloid deposits without cognitive 
decline $[4,14,27,34,50]$. In agreement with the normal cognitive state, our previous study observed normal spine density and dynamics on dendrites that were far away from amyloid plaques in deltaE9 mice at this age [58]. To further examine if activity-induced structural spine plasticity on these dendrites is disturbed in preclinical $\mathrm{AD}$, we housed deltaE9 mice at the age of 4-5 months under enriched environment (EE) over 5 weeks and monitored the apical tufts of layer $\mathrm{V}$ pyramidal neurons in the somatosensory cortex (Suppl. Figure 1). EE, which provides a spectrum of synaptic inputs and thus leads to adaptive synaptic alterations within the adult brain $[30,31$, 38], induced a steady increase of spine density in the control group (Fig. 1a, c). In contrast, EE failed to increase spine density in deltaE9 mice (Fig. 1a, c). Of note, unlike control mice demonstrating gradual decline in dendritic spine elimination upon $\mathrm{EE}$, the rate of spine elimination in deltaE9 mice remained unaltered (Fig. 1d). EE did not change the rate of spine formation in both groups (Fig. 1e). Moreover, during the imaging period, the density and dynamics of dendritic spines remained unchanged, when mice were housed under standard conditions (SC, Fig. 1b, c-e). Thus, EE-induced decrease in spine elimination and subsequent increase in spine density were absent in deltaE9 mice.

To find out how preexisting neural networks react to the stimulation of EE, we tracked the fate of dendritic spines that existed in the first imaging session over the whole period of enrichment. Interestingly, in control and deltaE9 genotypes, less preexisting spines survived when mice were housed under EE (Fig. 1f, g). This indicated a breakdown of the established neural networks in both groups during EE. Furthermore, the fate of spines that were newly formed in $\mathrm{EE}$ or $\mathrm{SC}$ was also monitored. A higher number of gained spines remained stable during $\mathrm{EE}$ in control mice, but not in deltaE9 mice (Fig. 1h-j). Also, a direct comparison between control and deltaE9 mice revealed that the elimination rate of newly gained dendritic spines induced by EE was higher in the AD mouse model (Suppl. Fig. 2). These results suggest the failure of building up novel neural networks induced by EE in deltaE9 group. Collectively, our data imply that the reorganization of neural networks upon $\mathrm{EE}$ is impaired in preclinical stages of $\mathrm{AD}$.

\section{Reduction of BACE1 in deltaE9 mice restores the response with an increase in spine density upon EE}

Full-length APP is processed to yield amyloid beta, the principal component of amyloid plaques, through sequential enzymatic cleavage by $\beta$ - and $\gamma$-secretases. To investigate if elevated amyloid beta levels contribute to the impaired adaptive spine plasticity in deltaE9 mice, we crossed deltaE9 mice with BACE1 knockout mice to obtain deltaE9 genotype containing a heterozygous BACE1 gene knockout (deltaE9/Bace $+/-$ ). BACE1 is the primary $\beta$-secretase. Of
Fig. 1 Adaptive plasticity of dendritic spines is impaired in deltaE9 mice. a, b Two-photon micrographs of GFP-labeled apical dendrites of layer V pyramidal neurons. Mice were housed in standard conditions (SC) and imaged twice in a week apart before being housed in enriched environment (EE) (a). In b, mice were housed in SC throughout the experiment. Empty or dark arrows point to eliminated or formed spines compared to previous imaging session. Blue arrowheads mark spines that existed in the first imaging session and were stable over the entire imaging period while red arrowheads represent gained spines in the first week of EE or matching period of SC that survived over the rest of imaging period. c-e Quantifications of relative spine density, fraction of eliminated or formed spines in mice housed under EE (above) or SC (below). f, $\mathbf{g}$ Fractions of spines from the first imaging session that remained stable during the whole imaging period. $\mathbf{h}, \mathbf{i}$ Fractions of gained spines in the first week of EE or matching period of SC that remained stable during the whole imaging period. $\mathbf{j}$ The data at day 43 from $\mathbf{h}$ and $\mathbf{j}$ were compared by one-way ANOVA. Scale bar $2 \mu \mathrm{m}$

note, the density and dynamics of dendritic spines in deltaE9/Bace +/- genotype remained unchanged compared to control or deltaE9 mice, when they were housed under SC (Suppl. Fig. 3b-d). Partial reduction of BACE1 activity dramatically reduced amyloid plaques, glial cell activation and amyloid pathology (Fig. 2, Suppl. Fig. 4 and Suppl. Fig. 5). Unlike deltaE9 group, deltaE9/Bace $+/-$ mice gained the adaptive increase in spine density housed under EE (Fig. 3a, b). To our surprise, the increase in spine density was caused by boosting spine formation (Fig. 3e) instead of decreasing spine elimination (Fig. 3d), which was opposite to the observations in the control group (Fig. 1d, e). In addition, the fates of spines that existed before or were newly formed after EE were indistinguishable between different housing conditions (Fig. 3f, g). An increased fraction of transient spines (Fig. 3c) suggested that the newly gained spines induced by EE were unstable over 1 week. In deltaE9 or control mice, the increased transient fraction during EE was not observed (data not shown). Taken together, EE induced spine density increase but failed to remodel neural circuits in deltaE9/Bace $+/-$ mice. These deficits in neural network remodeling appear to be caused by the reduction of $\beta$-secretase, as similar findings have been observed in Bace $+/-$ mice (Suppl. Figure 6). The restoration of adaptive spine density increase suggests removal of amyloid plaques might ameliorate the impaired adaptive plasticity of dendritic spines in preclinical AD.

\section{Pioglitazone rescues the deficits of adaptive dendritic spine plasticity in deltaE9 mice}

As the imaged dendrites were located in amyloid plaquefree brain regions [58], it was plausible to hypothesize that diffusible factors originating from amyloid deposits might contribute to the lack of response of spine density upon EE, which was restored by the removal of plaques (Fig. 3b). Particularly, it is known that amyloid plaques are surrounded by activated glial cells that are known to 

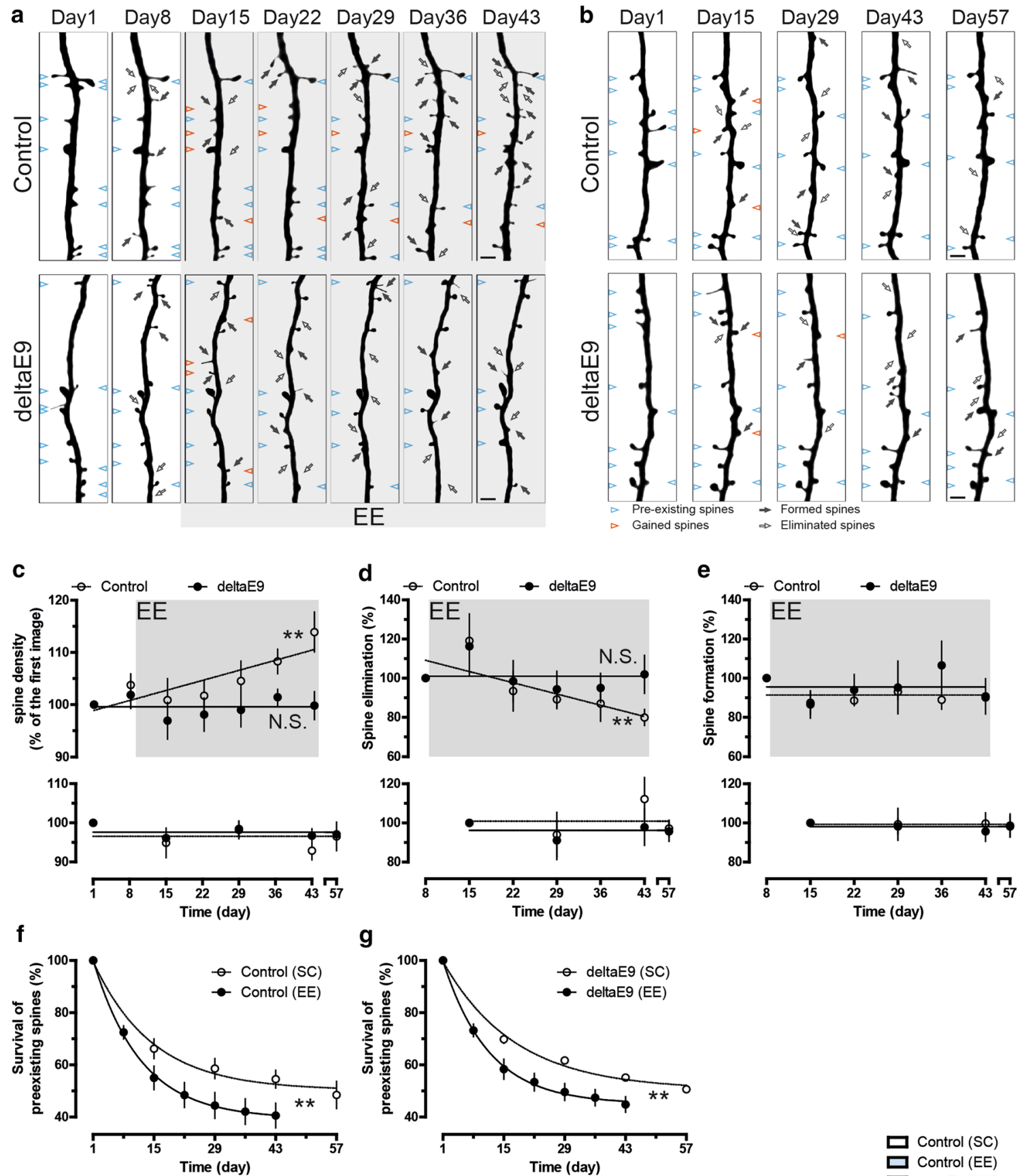

g
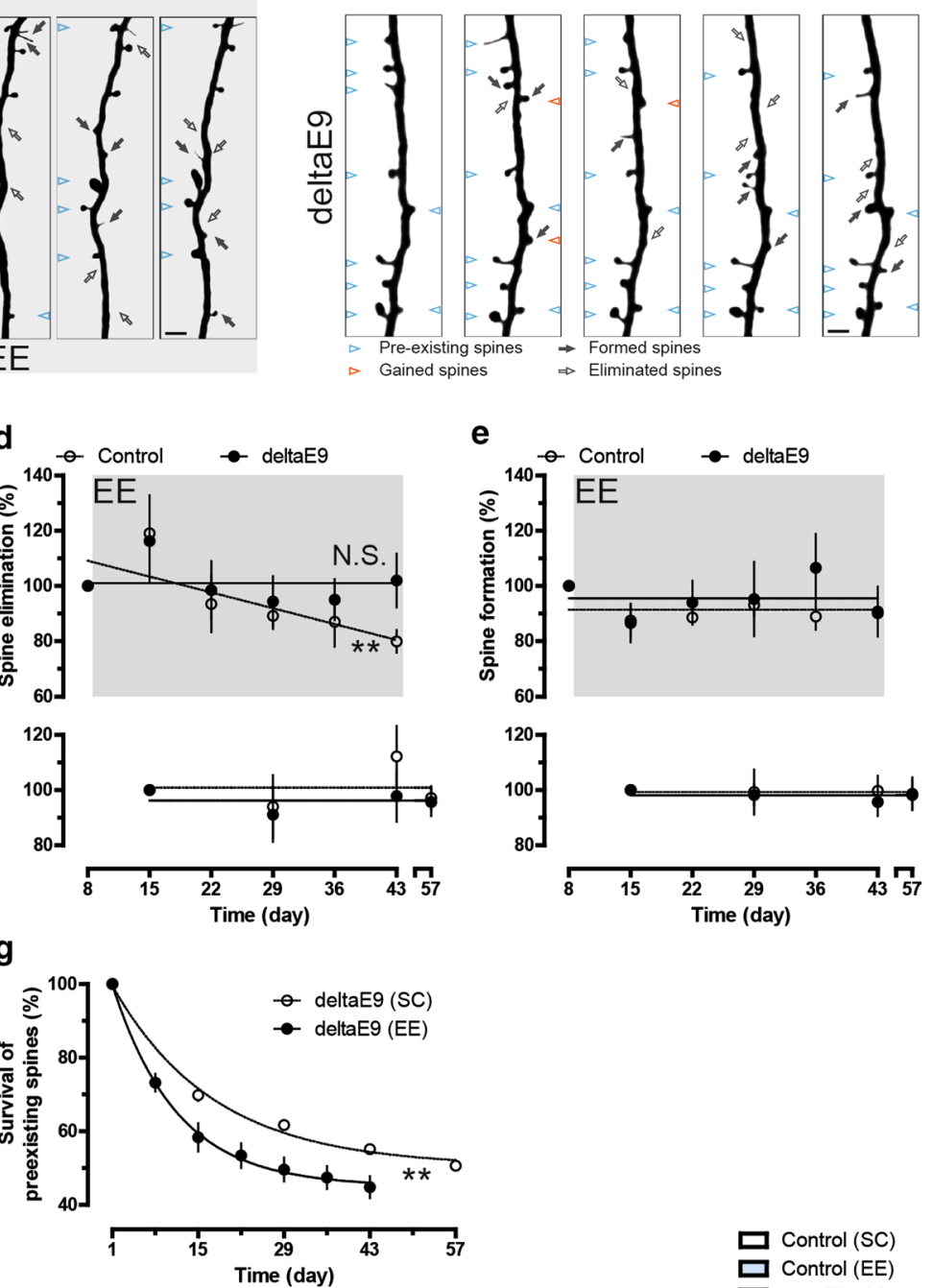

h

i
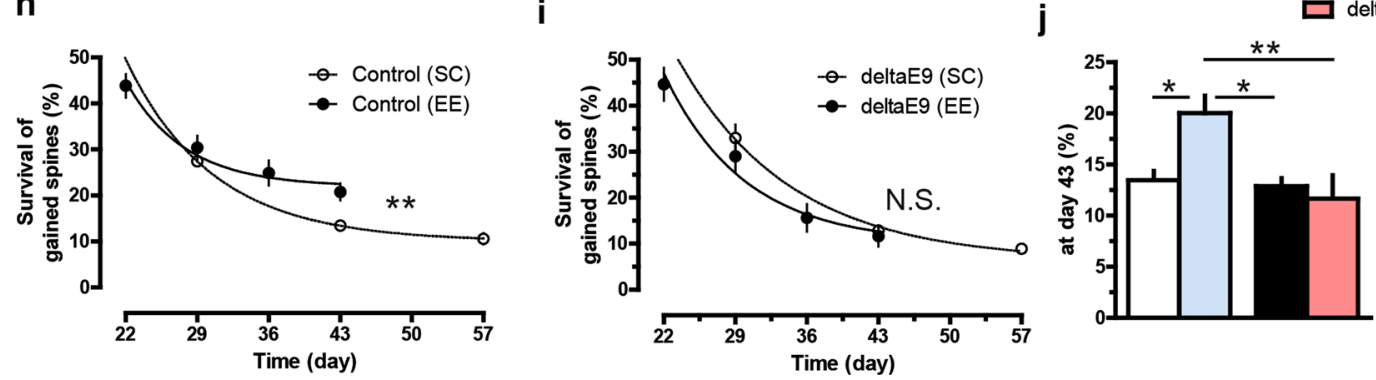
Fig. 2 Partial reduction of BACE1 in deltaE9 mice greatly decreases amyloid plaque load and subsequent glial cell activation. a Immunohistochemical labeling of amyloid plaques (blue) and activated astrocytes (GFAP, red) or microglia (Iba-1, red) in the cortex. Scale bar $300 \mu \mathrm{m}$. b-d Quantifications of area with plaque load and activated glial cells in deltaE9 and deltaE9/Bace $+/-$ mice at the age of 6-7 months a
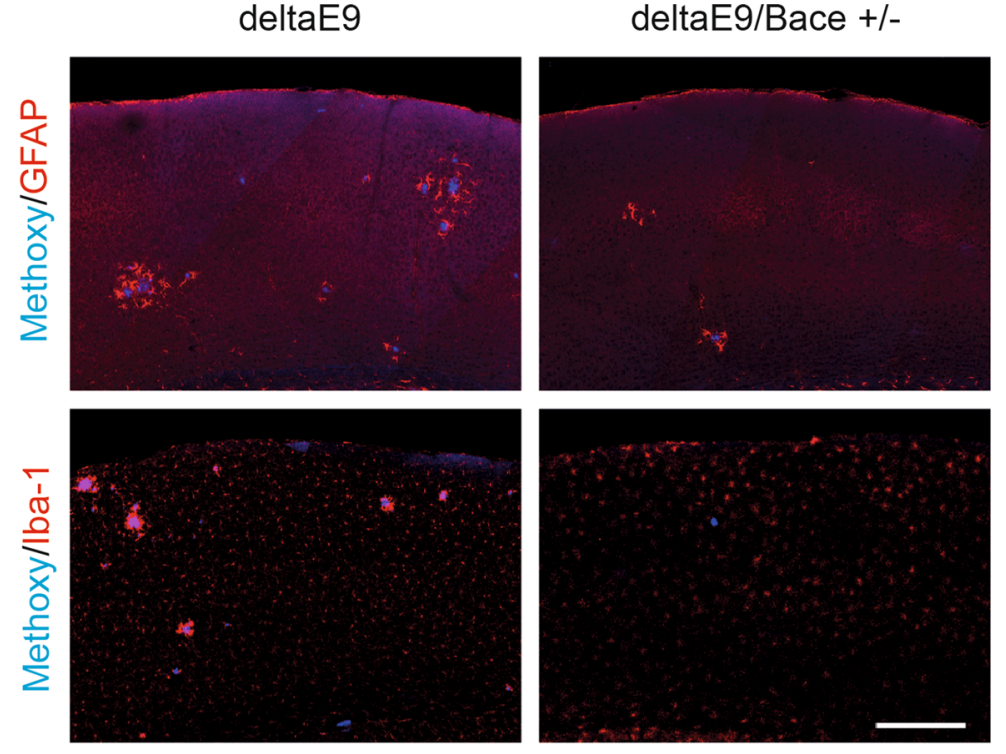

b

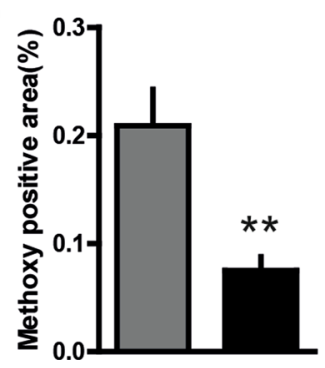

C

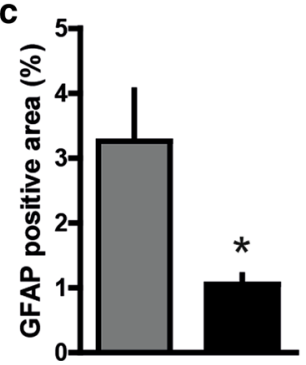

deltaE9/Bace +/-

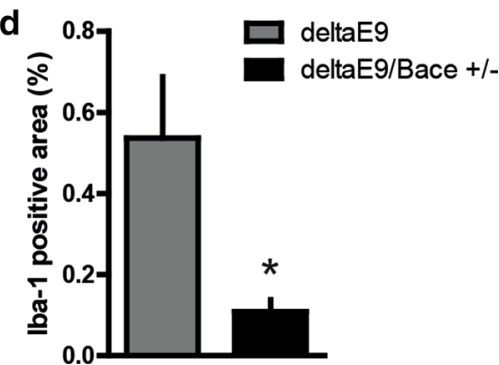

release pro-inflammatory cytokines [53]. To investigate if these cytokines caused the impaired adaptive plasticity, we treated deltaE9 mice with pioglitazone, a PPAR-gamma agonist, which inhibits the production of pro-inflammatory cytokines without affecting synaptic plasticity [6, 25] (Suppl. Figure 7). Pioglitazone treatment successfully rehabilitated the steady increase of spine density in deltaE9 mice during exposure to EE (Fig. 4a, b). Like in control mice, the EE-induced spine density increase resulted from the gradual decline in spine elimination, while the rate of spine formation was unchanged (Fig. 4d, e). Moreover, less preexisting spines and more gained spines were observed during EE, when deltaE9 mice were fed with pioglitazone (Fig. 4f, g). The fraction of transient spines also remained unchanged (Fig. 4c). These results indicate that the failure of remodeling neural networks upon EE in deltaE9 mice is ascribed to the up-regulation of pro-inflammatory cytokines.

\section{IL-1 RA rehabilitates the impaired adaptive plasticity of dendritic spines in deltaE9 mice}

The known deleterious effects of interleukin-1 $\beta$ (IL-1 $\beta$ ), a key mediator of the inflammatory response in $\mathrm{AD}$, on synaptic plasticity [48] prompted us to examine whether up-regulated levels of IL- $1 \beta$ undermined the adaptive spine plasticity. Consistent with previous reports [33, 47, 55], the expression of IL-1 $\beta$ was indeed significantly enhanced in deltaE9 mice (Fig. 5a). To diminish IL-1 $\beta$ activity, we injected lentivirus (LV) expressing interleukin-1 receptor antagonist (IL-1 RA) [49] into the somatosensory cortex (Fig. 5b). IL-1 RA has previously been found not to alter spine density, LTP, spatial memory and synaptic markers in wild-type mice [9]. In this study, we found that IL-1 RA rectified the adaptive gain of spines upon $\mathrm{EE}$ in deltaE9 mice, accompanied with the gradual decline in spine elimination instead of rising spine formation (Fig. 6a, b, d, e). Also, the fate of spines that existed before or newly formed during EE was normalized in deltaE9 mice administered with IL-1 RA (Fig. 6f, g). In addition, the fraction of transient spines was unchanged (Fig. 6c). Taken together, these data suggest up-regulated IL-1 $\beta$ perturbs EE-induced reorganization of neural networks.

\section{Discussion}

As excitatory postsynaptic compartments, dendritic spines receive and integrate informational input from presynaptic terminals [57]. This function is supposed to be disturbed 
Fig. 3 Reduction of BACE1

restores the spine density increase, but not neural circuit remodeling, upon EE in deltaE9 mice. a Two-photon micrographs of GFP-labeled apical dendrites. DeltaE9/Bace $+/-$ mice were housed under $\mathrm{SC}$ (above) or EE (below). Empty or dark arrows point to eliminated or formed spines compared to previous imaging session. Blue arrowheads mark spines that existed in the first imaging session and were stable over the entire imaging period, whereas red arrowheads represent gained spines in the first week of EE or matching period of SC that survived over the rest of imaging period. b-e Quantifications of relative spine density, fraction of transient, eliminated or formed spines. f, $\mathbf{g}$ Fraction of spines in the first imaging session or gained spines in the first week of EE and matching week of SC that survived over the imaging period. Scale bar $2 \mu \mathrm{m}$ a
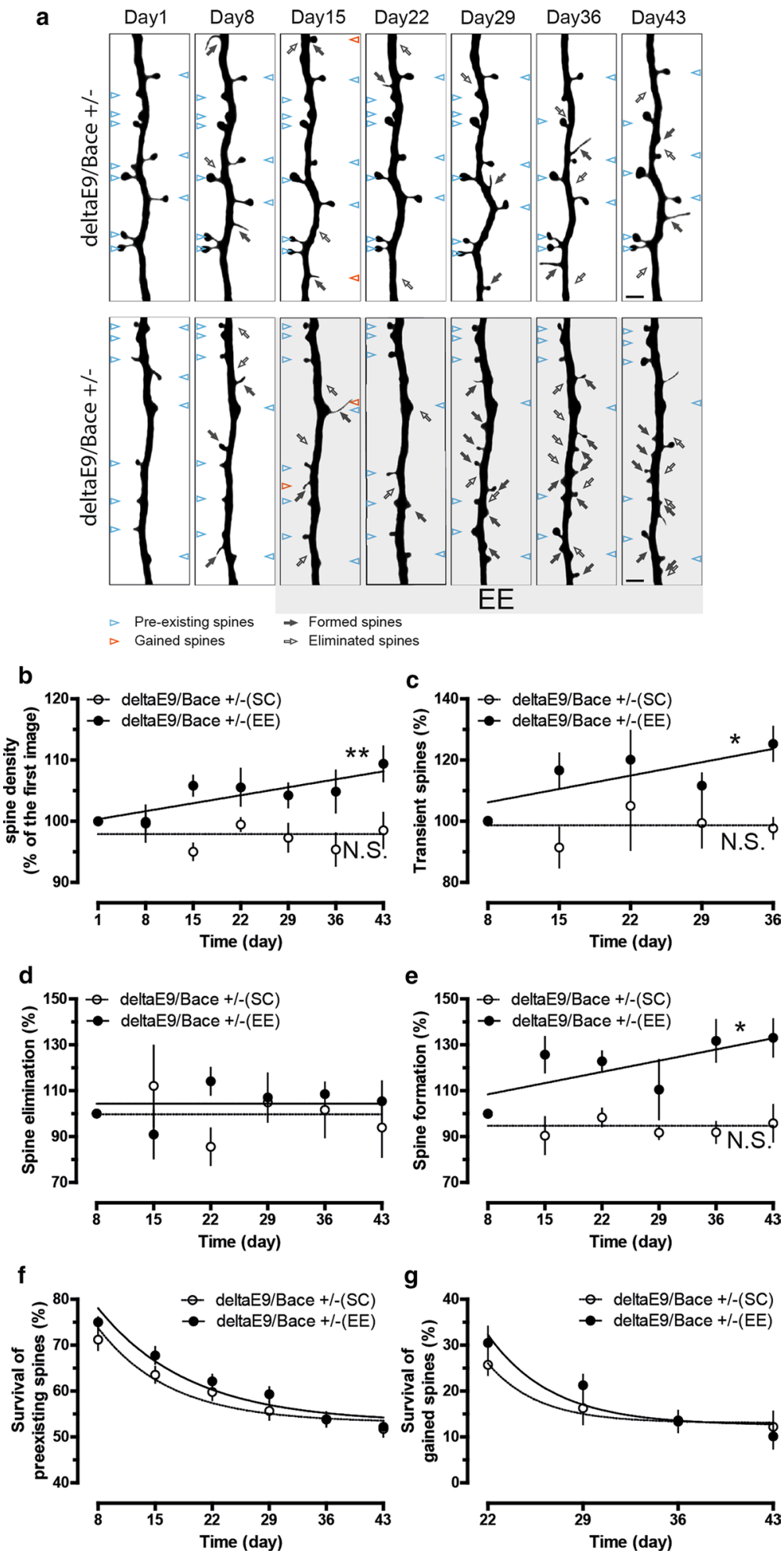

at the very early stages of $\mathrm{AD}$ pathogenesis, which may explain why synaptic loss is a much better indicator for cognitive impairment in $\mathrm{AD}$ than $\mathrm{A} \beta$ burden or neuronal loss [41]. With the advent of cognitive decline, irreversible damage may have already occurred. Prevention strategies in the asymptomatic stages of $\mathrm{AD}$ are therefore warranted. 
Fig. 4 Pioglitazone recovers the observed impairments of spine structural plasticity in deltaE9 mice. a Two-photon micrographs of GFP-labeled apical dendrites. DeltaE9 mice were fed with pioglitazone during EE or a matching period of SC. Empty or dark arrows point to eliminated or formed spines compared to previous imaging session. Blue arrowheads mark spines that existed in the first imaging session and were stable over the entire imaging period while red arrowheads represent gained spines in the first week of EE or matching period of SC that survived over the rest of imaging period. b-e Quantifications of relative spine density, fraction of transient, eliminated or formed spines. $\mathbf{f}, \mathbf{g}$ Fraction of spines in the first imaging session or gained spines in the first week of EE and matching week of SC that survived over the imaging period. Scale bar $2 \mu \mathrm{m}$ a
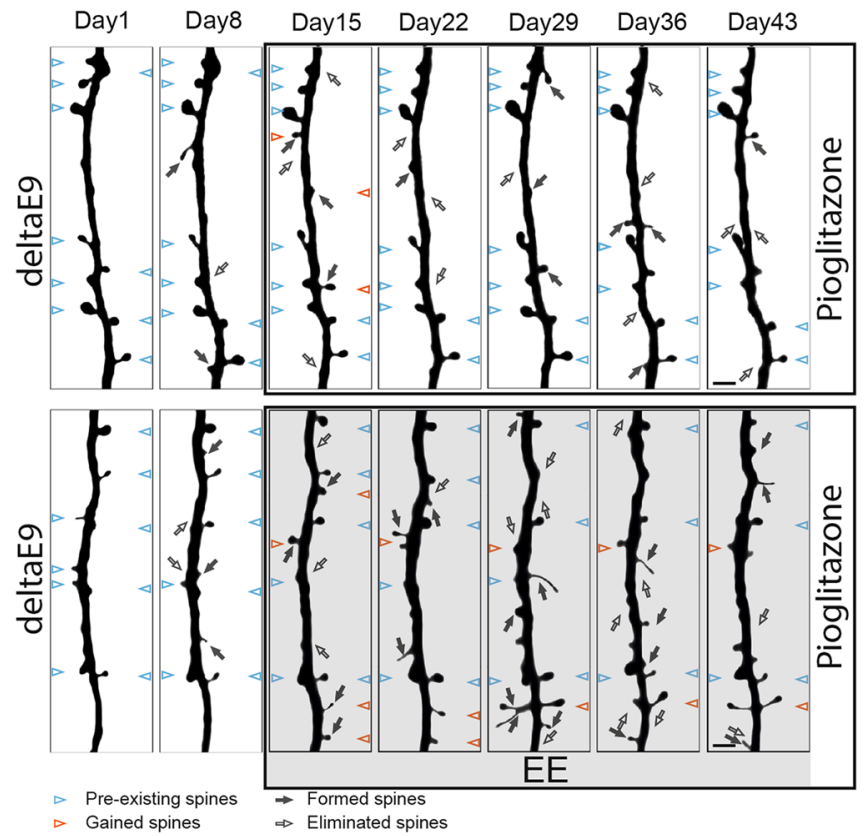

b
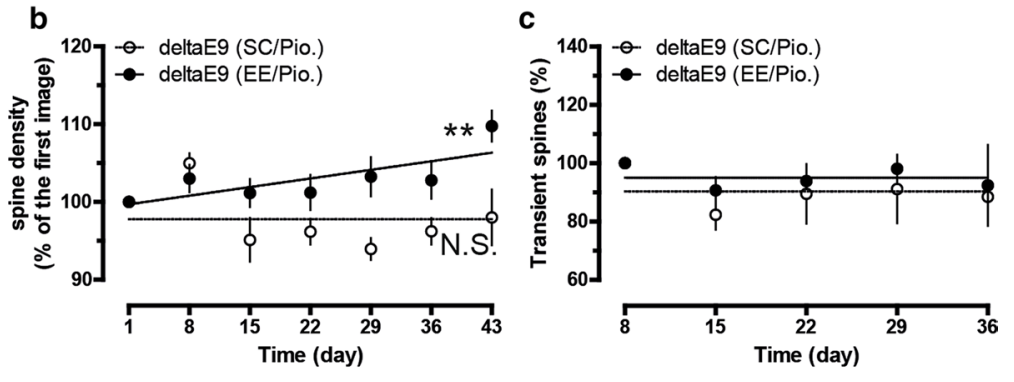

。
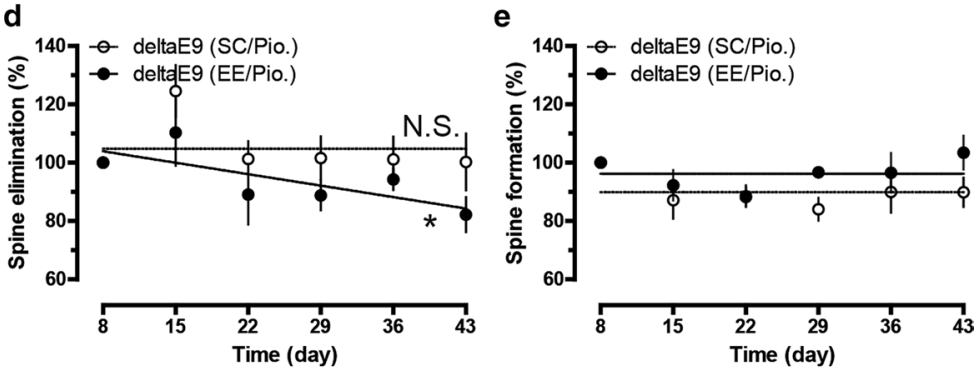

f
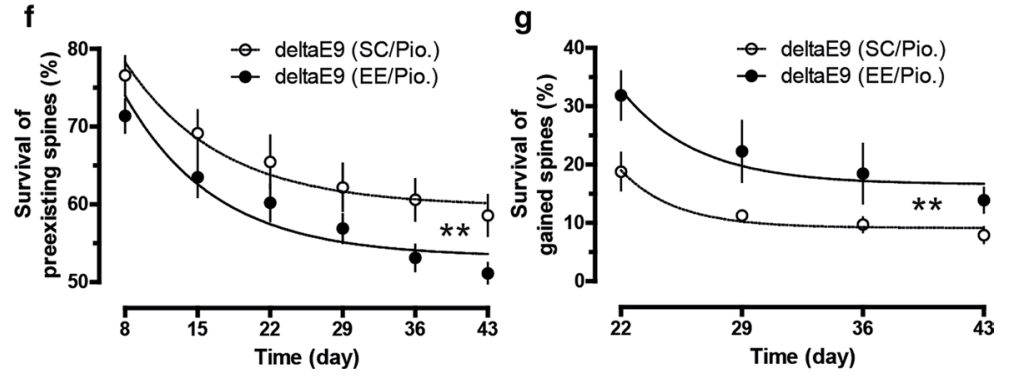

Preclinical AD is replicated in young deltaE9 mice that develop amyloid deposits before the onset of cognitive decline $[4,14,27,34,50]$. In this study, we found that 4-5-month-old deltaE9 mice did not increase dendritic spine density when housed under EE in contrast to control mice. The novel external environment also failed to remodel neural networks in these transgenic mice. Reduction of BACE1 activity in deltaE9 mice reduced the 
Fig. 5 Elevated expression of interleukin- $1 \beta$ in deltaE9 mice and exogenous interleukin-1 receptor antagonist produced by lentivirus infection. a By quantitative real-time PCR (left) and western blot (right), the expression of interleukin-1 $\beta$ (IL-1 $\beta$ ) was found to be increased in deltaE9 mice. b Interleukin-1 receptor antagonist (IL-1 RA) was overexpressed in somatosensory cortex after 1 month of lentivirus injection, as illustrated by western blot images and quantification

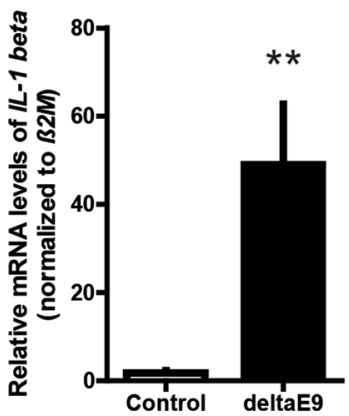

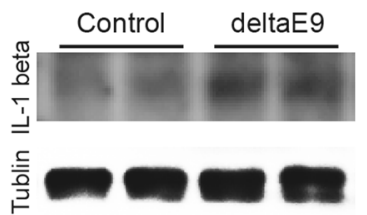

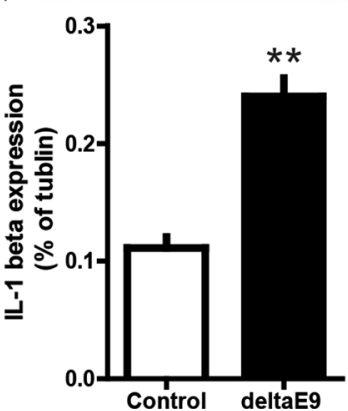

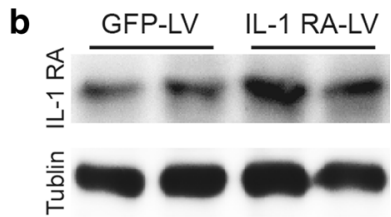

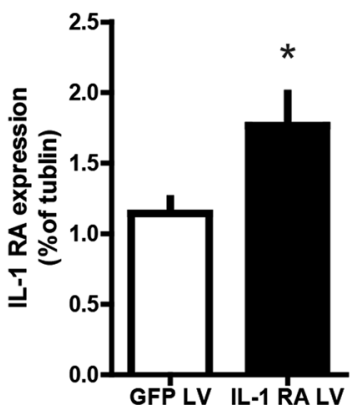

deposition of $\mathrm{A} \beta$ and restored the increase of spine density during EE, but not the impaired reorganization of neural networks. However, anti-inflammatory treatments, pioglitazone and IL-1 RA, successfully rescued the spine density increase and neural network remodeling upon $\mathrm{EE}$ in deltaE9 mice. These results suggest that neuroinflammation contributes to impaired adaptive plasticity of dendritic spines in preclinical stages of AD.

Structural plasticity of dendritic spines refers to the change of their distribution in response to experience [12]. Learning and sensory experience have been reported to remodel neural connections through de novo growth and loss of dendritic spines, which provides a structural substrate for adaptive behaviors. Spine density increases after spatial learning tasks or manipulations that intensify sensory inputs [26, 28], while deprivation of sensory experience leads to a decrease in spine density [52]. This structural synaptic plasticity may substantially boost information storage capacity in the brain [7]. The failure to increase spine density in young adult deltaE9 mice upon EE suggests an impairment of experience-dependent structural plasticity in asymptomatic stages of $\mathrm{AD}$, before spine loss occurs. In addition, stabilized newly formed spines and destabilized preexisting spines in novel experience reflect a rewiring of neural networks, which facilitates a quicker adaption of brain to the same situation in the future [19, $54,56]$. Interestingly, the ability to dismantle the preexisting neural networks in novel external environment remains intact in deltaE9 mice. However, deltaE9 mice fall short of the establishment of novel neural networks. These results imply that experience-dependent demolition and construction of neural networks are two processes that are independent from each other.

BACE1 initiates the proteolytic process of APP into $\mathrm{A} \beta$, which accumulates to form amyloid plaques. As $A \beta$ is believed to play a central role in AD, BACE1 becomes an attractive drug target. Indeed, partial reduction of BACE1 activity leads to dramatic reductions on amyloid plaque burden and synaptic deficits with a small decrease of $\mathrm{A} \beta$ levels in young AD transgenic mice [29]. However, pharmacological inhibition of BACE1 impairs structural and functional synaptic plasticity implying its physiological role in dendritic spines [11]. The boosted transient spines, which contribute to increased spine formation, in deltaE9/ Bace $+/-$ mice during EE indicate the maintenance of experience-dependent synaptic rearrangement requires physiological level of BACE1 activity. It still remains unclear, whether BACE1 itself or its substrates are involved in synaptic physiology.

Amyloid deposition, driving neuroinflammation, is associated with activated glial cells and the release of proinflammatory cytokines. These soluble mediators, IL-1 $\beta$ in particular, directly and extensively disturb synaptic transmission and plasticity. IL-1 $\beta$ regulates the expression and phosphorylation of glutamate receptors on dendritic spines [36]. The altered sensitivity of receptors to synaptic glutamate modulates synaptic plasticity. In addition, IL-1 $\beta$ disrupts BDNF signaling cascades and thereby prevents activity-driven formation of filamentous actin in spines, which is required for spine structural plasticity [48]. The restorative effects of pioglitazone and IL-1 RA demonstrated herein implicate a deleterious role of IL-1 $\beta$ in experiencedependent spine structural plasticity preceding cognitive impairment in AD.

Of note, numerous clinical studies have demonstrated that anti-inflammatory treatment reduces dementia risk or delay the onset of $\mathrm{AD}[3,8,18]$, although anti-inflammatory drugs in clinically manifested AD failed to be proven effective $[15,24]$. These trials suggest prevention of inflammatory processes is beneficial at the preclinical stages of AD. Our data confirm that neuroinflammation caused impairments of spine structural plasticity is curable by anti-inflammatory treatment in a preclinical mouse model of AD. This finding implies the normalization of adaptive 
Fig. 6 IL-1 RA rescues the impaired adaptive plasticity of dendritic spines in deltaE9 mice. a Two-photon micrographs of GFP-labeled apical dendrites of layer $\mathrm{V}$ pyramidal neurons. Mice were housed in SC (above) or EE (below). Empty or dark arrows point to eliminated or formed spines compared to previous imaging session. Blue arrowheads mark spines that existed in the first imaging session and were stable over the entire imaging period while red arrowheads represent gained spines in the first week of EE or matching period of SC that survived over the rest of imaging period. b-e Quantifications of relative spine density, fraction of transient, eliminated or formed spines. f, $\mathbf{g}$ Fraction of spines in the first imaging session or gained spines in the first week of EE and matching week of SC that survived over the imaging period. Scale bar, $2 \mu \mathrm{m}$ a
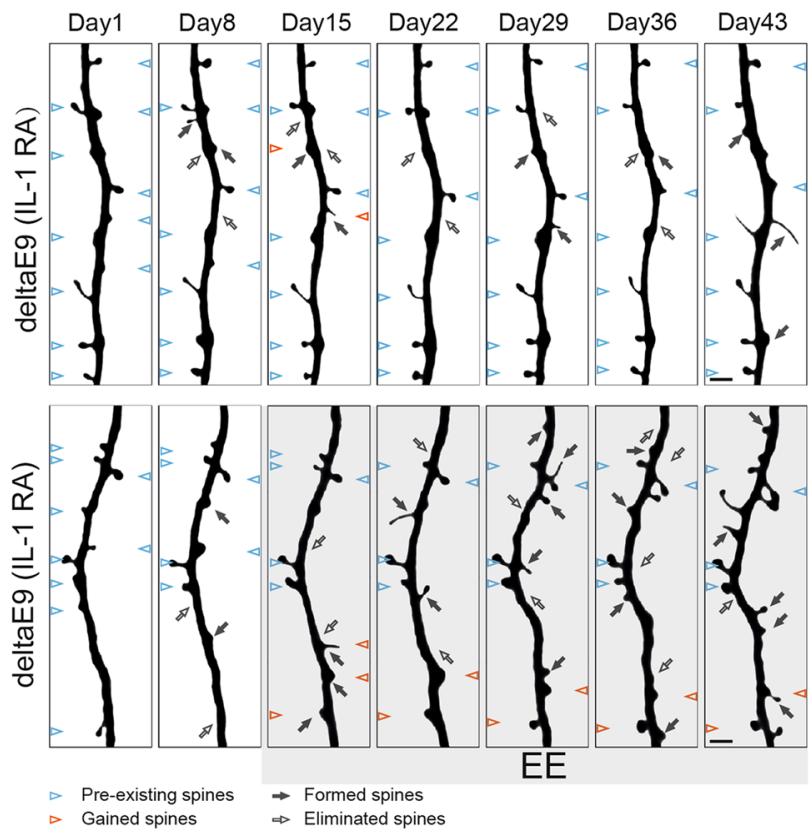

b

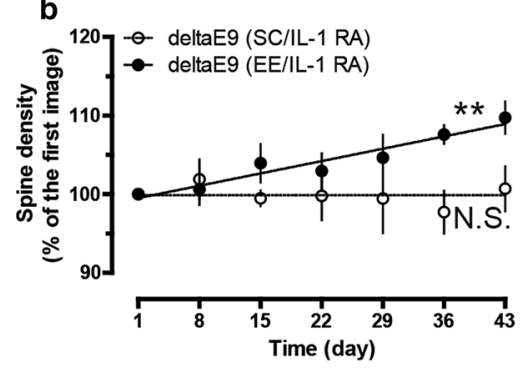

d
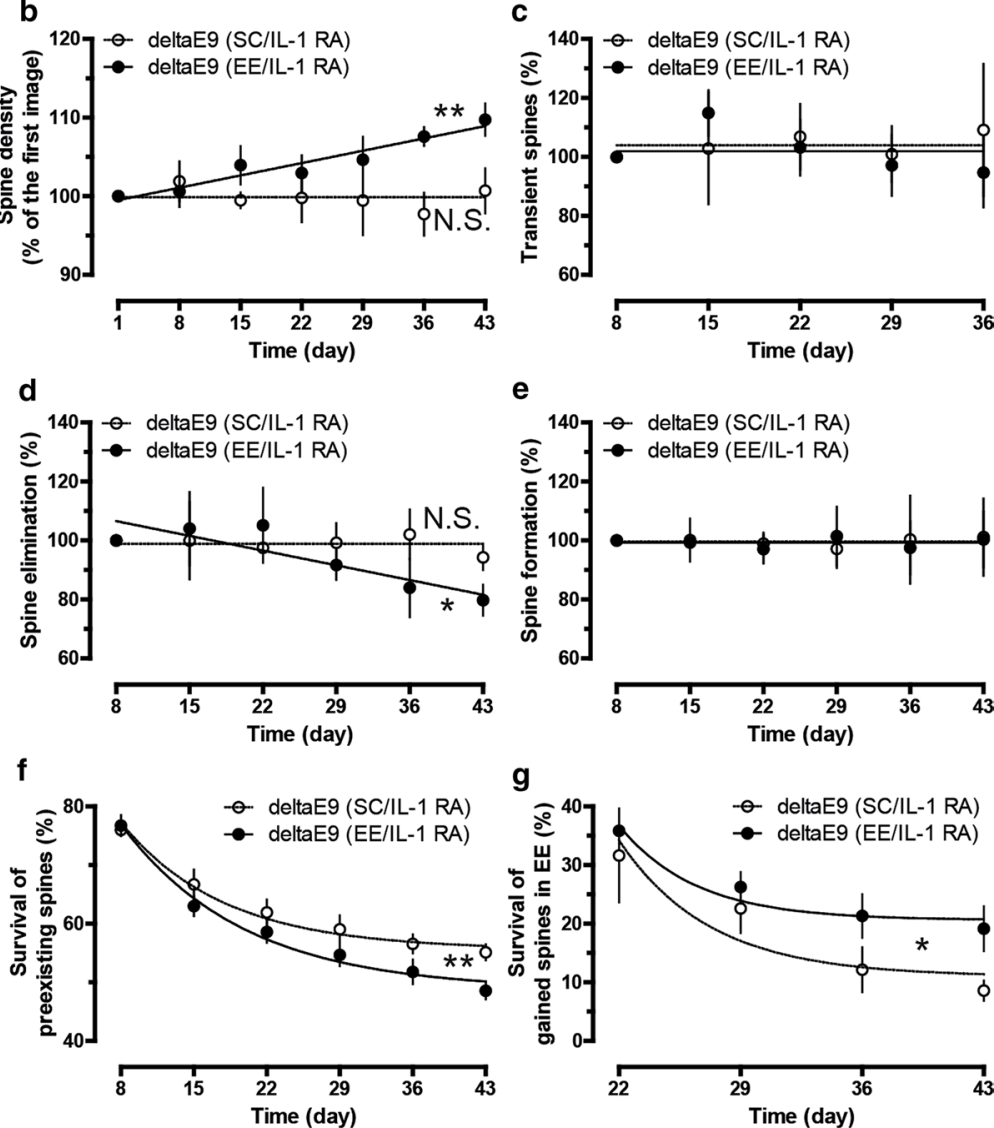

e

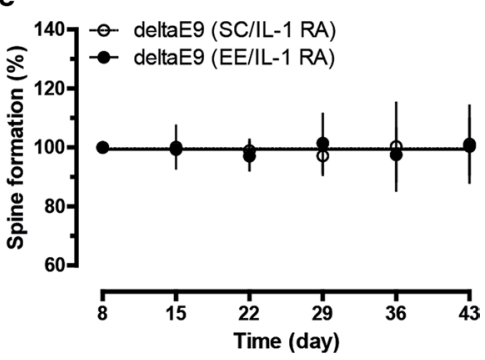

g

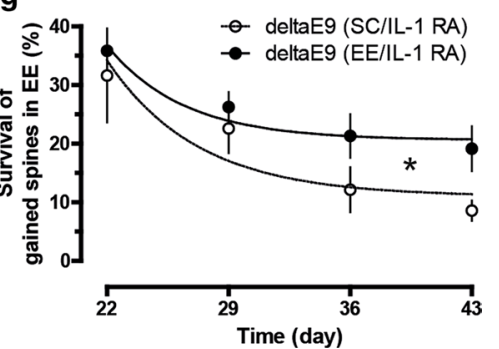

structural plasticity of dendritic spines may correlate with the beneficial effects of anti-inflammatory treatment in preclinical AD patients.
We conclude that our in vivo dendritic spine analysis reveals that neuroinflammation, caused by amyloid deposition, undermines the adaptive changes of neural networks 
upon novel external environment before the occurrence of dementia, providing new insights for a possible benefit of anti-inflammatory treatments in preclinical AD.

Acknowledgments We would like to thank Sonja Steinbach, Eric Griessinger, and Katharina Bayer for their excellent technical support and animal care. Furthermore, we thank Severin Filser for helpful advice in planning the experiments and preparing the manuscript. This work was funded by the German Federal Ministry of Education and Research (Bundesministerium für Bildung und Forschung, project $13 \mathrm{~N} 12778$ and $0316033 \mathrm{C}$ and the European commission within the 7 th framework (Extrabrain -606950).

\section{Compliance with ethical standards}

Conflict of interest The authors declare that they have no conflict of interests.

Open Access This article is distributed under the terms of the Creative Commons Attribution 4.0 International License (http://creativecommons.org/licenses/by/4.0/), which permits unrestricted use, distribution, and reproduction in any medium, provided you give appropriate credit to the original author(s) and the source, provide a link to the Creative Commons license, and indicate if changes were made.

\section{References}

1. Ashe KH, Zahs KR (2010) Probing the biology of Alzheimer's disease in mice. Neuron 66:631-645. doi:10.1016/j. neuron.2010.04.031

2. Bilkei-Gorzo A (2014) Genetic mouse models of brain ageing and Alzheimer's disease. Pharmacol Ther 142:244-257. doi:10.1016/j.pharmthera.2013.12.009

3. Breitner JC, Welsh KA, Helms MJ, Gaskell PC, Gau BA, Roses AD, Pericak-Vance MA, Saunders AM (1995) Delayed onset of Alzheimer's disease with nonsteroidal anti-inflammatory and histamine $\mathrm{H} 2$ blocking drugs. Neurobiol Aging 16:523-530

4. Burgess BL, McIsaac SA, Naus KE, Chan JY, Tansley GH, Yang J, Miao F, Ross CJ, van Eck M, Hayden MR et al (2006) Elevated plasma triglyceride levels precede amyloid deposition in Alzheimer's disease mouse models with abundant A beta in plasma. Neurobiol Dis 24:114-127. doi:10.1016/j.nbd.2006.06.007

5. Cai H, Wang Y, McCarthy D, Wen H, Borchelt DR, Price DL, Wong PC (2001) BACE1 is the major beta-secretase for generation of Abeta peptides by neurons. Nat Neurosci 4:233-234. doi:10.1038/85064

6. Chen J, Li S, Sun W, Li J (2015) Anti-diabetes drug pioglitazone ameliorates synaptic defects in AD transgenic mice by inhibiting cyclin-dependent kinase5 activity. PLoS One 10:e0123864. doi:10.1371/journal.pone.0123864

7. Chklovskii DB, Mel BW, Svoboda K (2004) Cortical rewiring and information storage. Nature 431:782-788. doi:10.1038/ nature 03012

8. Cote S, Carmichael PH, Verreault R, Lindsay J, Lefebvre J, Laurin D (2012) Nonsteroidal anti-inflammatory drug use and the risk of cognitive impairment and Alzheimer's disease. Alzheimer's Dement J Alzheimer's Assoc 8:219-226. doi:10.1016/j. jalz.2011.03.012

9. Erion JR, Wosiski-Kuhn M, Dey A, Hao S, Davis CL, Pollock NK, Stranahan AM (2014) Obesity elicits interleukin 1-mediated deficits in hippocampal synaptic plasticity. J Neurosci 34:26182631. doi:10.1523/JNEUROSCI.4200-13.2014
10. Feng G, Mellor RH, Bernstein M, Keller-Peck C, Nguyen QT, Wallace M, Nerbonne JM, Lichtman JW, Sanes JR (2000) Imaging neuronal subsets in transgenic mice expressing multiple spectral variants of GFP. Neuron 28:41-51

11. Filser S, Ovsepian SV, Masana M, Blazquez-Llorca L, Brandt Elvang A, Volbracht C, Muller MB, Jung CK, Herms J (2015) Pharmacological inhibition of BACE1 impairs synaptic plasticity and cognitive functions. Biol Psychiatry 77:729-739. doi:10.1016/j.biopsych.2014.10.013

12. Fu M, Zuo Y (2011) Experience-dependent structural plasticity in the cortex. Trends Neurosci 34:177-187. doi:10.1016/j. tins.2011.02.001

13. Fuhrmann M, Mitteregger G, Kretzschmar H, Herms J (2007) Dendritic pathology in prion disease starts at the synaptic spine. J Neurosci 27:6224-6233. doi:10.1523/ JNEUROSCI.5062-06.2007

14. Garcia-Alloza M, Robbins EM, Zhang-Nunes SX, Purcell SM, Betensky RA, Raju S, Prada C, Greenberg SM, Bacskai BJ, Frosch MP (2006) Characterization of amyloid deposition in the APPswe/PS1dE9 mouse model of Alzheimer disease. Neurobiol Dis 24:516-524. doi:10.1016/j.nbd.2006.08.017

15. Group ADC, Bentham P, Gray R, Sellwood E, Hills R, Crome P, Raftery J (2008) Aspirin in Alzheimer's disease (AD2000): a randomised open-label trial. Lancet Neurol 7:41-49. doi:10.1016/ S1474-4422(07)70293-4

16. Hardy J, Selkoe DJ (2002) The amyloid hypothesis of Alzheimer's disease: progress and problems on the road to therapeutics. Science 297:353-356. doi:10.1126/science.1072994

17. Hedden T, Van Dijk KR, Becker JA, Mehta A, Sperling RA, Johnson KA, Buckner RL (2009) Disruption of functional connectivity in clinically normal older adults harboring amyloid burden. J Neurosci 29:12686-12694. doi:10.1523/ JNEUROSCI.3189-09.2009

18. Heneka MT, Fink A, Doblhammer G (2015) Effect of pioglitazone medication on the incidence of dementia. Ann Neurol 78:284-294. doi:10.1002/ana.24439

19. Hofer SB, Mrsic-Flogel TD, Bonhoeffer T, Hubener M (2009) Experience leaves a lasting structural trace in cortical circuits. Nature 457:313-317. doi:10.1038/nature07487

20. Holtmaat A, Bonhoeffer T, Chow DK, Chuckowree J, De Paola V, Hofer SB, Hubener M, Keck T, Knott G, Lee WC et al (2009) Long-term, high-resolution imaging in the mouse neocortex through a chronic cranial window. Nat Protoc 4:1128-1144. doi:10.1038/nprot.2009.89

21. Huang Y, Mucke L (2012) Alzheimer mechanisms and therapeutic strategies. Cell 148:1204-1222. doi:10.1016/j. cell.2012.02.040

22. Jankowsky JL, Fadale DJ, Anderson J, Xu GM, Gonzales V, Jenkins NA, Copeland NG, Lee MK, Younkin LH, Wagner SL et al (2004) Mutant presenilins specifically elevate the levels of the 42 residue beta-amyloid peptide in vivo: evidence for augmentation of a 42-specific gamma secretase. Hum Mol Genet 13:159-170. doi:10.1093/hmg/ddh019

23. Jankowsky JL, Slunt HH, Ratovitski T, Jenkins NA, Copeland NG, Borchelt DR (2001) Co-expression of multiple transgenes in mouse CNS: a comparison of strategies. Biomol Eng $17: 157-165$

24. Jaturapatporn D, Isaac MG, McCleery J, Tabet N (2012) Aspirin, steroidal and non-steroidal anti-inflammatory drugs for the treatment of Alzheimer's disease. Cochrane Database Syst Rev 2:CD006378. doi:10.1002/14651858.CD006378.pub2

25. Jiang C, Ting AT, Seed B (1998) PPAR-gamma agonists inhibit production of monocyte inflammatory cytokines. Nature 391:8286. doi: $10.1038 / 34184$

26. Jung CK, Herms J (2014) Structural dynamics of dendritic spines are influenced by an environmental enrichment: an in vivo 
imaging study. Cereb Cortex 24:377-384. doi:10.1093/cercor/ bhs 317

27. Lalonde R, Kim HD, Fukuchi K (2004) Exploratory activity, anxiety, and motor coordination in bigenic APPswe + PS1/ DeltaE9 mice. Neurosci Lett 369:156-161. doi:10.1016/j. neulet.2004.07.069

28. Leuner B, Falduto J, Shors TJ (2003) Associative memory formation increases the observation of dendritic spines in the hippocampus. J Neurosci 23:659-665

29. McConlogue L, Buttini M, Anderson JP, Brigham EF, Chen KS, Freedman SB, Games D, Johnson-Wood K, Lee M, Zeller $M$ et al (2007) Partial reduction of BACE1 has dramatic effects on Alzheimer plaque and synaptic pathology in APP Transgenic Mice. J Biol Chem 282:26326-26334. doi:10.1074/jbc. M611687200

30. Mora F, Segovia G, del Arco A (2007) Aging, plasticity and environmental enrichment: structural changes and neurotransmitter dynamics in several areas of the brain. Brain Res Rev 55:78-88. doi:10.1016/j.brainresrev.2007.03.011

31. Nithianantharajah J, Hannan AJ (2006) Enriched environments, experience-dependent plasticity and disorders of the nervous system. Nat Rev Neurosci 7:697-709. doi:10.1038/nrn1970

32. Oh H, Habeck C, Madison C, Jagust W (2014) Covarying alterations in Abeta deposition, glucose metabolism, and gray matter volume in cognitively normal elderly. Hum Brain Mapp 35:297308. doi:10.1002/hbm. 22173

33. Park SM, Shin JH, Moon GJ, Cho SI, Lee YB, Gwag BJ (2011) Effects of collagen-induced rheumatoid arthritis on amyloidosis and microvascular pathology in APP/PS1 mice. BMC Neurosci 12:106. doi:10.1186/1471-2202-12-106

34. Reiserer RS, Harrison FE, Syverud DC, McDonald MP (2007) Impaired spatial learning in the APPSwe + PSEN1DeltaE9 bigenic mouse model of Alzheimer's disease. Genes Brain Behav 6:54-65. doi:10.1111/j.1601-183X.2006.00221.x

35. Riedel WJ (2014) Preventing cognitive decline in preclinical Alzheimer's disease. Curr Opin Pharmacol 14:18-22. doi:10.1016/j. coph.2013.10.002

36. Rossi S, Motta C, Musella A, Centonze D (2014) The interplay between inflammatory cytokines and the endocannabinoid system in the regulation of synaptic transmission. Neuropharmacology 96:105-112. doi:10.1016/j.neuropharm.2014.09.022

37. Rowe CC, Ellis KA, Rimajova M, Bourgeat P, Pike KE, Jones G, Fripp J, Tochon-Danguy H, Morandeau L, O'Keefe G et al (2010) Amyloid imaging results from the Australian Imaging, Biomarkers and Lifestyle (AIBL) study of aging. Neurobiol Aging 31:1275-1283. doi:10.1016/j.neurobiolaging.2010.04.007

38. Sale A, Berardi N, Maffei L (2014) Environment and brain plasticity: towards an endogenous pharmacotherapy. Physiol Rev 94:189-234. doi:10.1152/physrev.00036.2012

39. Savonenko A, Xu GM, Melnikova T, Morton JL, Gonzales V, Wong MP, Price DL, Tang F, Markowska AL, Borchelt DR (2005) Episodic-like memory deficits in the APPswe/PS1dE9 mouse model of Alzheimer's disease: relationships to beta-amyloid deposition and neurotransmitter abnormalities. Neurobiol Dis 18:602-617. doi:10.1016/j.nbd.2004.10.022

40. Selkoe DJ (2011) Alzheimer's disease. Cold Spring Harb Perspect Biol. doi:10.1101/cshperspect.a004457

41. Selkoe DJ (2002) Alzheimer's disease is a synaptic failure. Science 298:789-791. doi:10.1126/science.1074069

42. Sheline YI, Raichle ME, Snyder AZ, Morris JC, Head D, Wang S, Mintun MA (2010) Amyloid plaques disrupt resting state default mode network connectivity in cognitively normal elderly. Biol Psychiatry 67:584-587. doi:10.1016/j.biopsych.2009.08.024

43. Sperling R, Mormino E, Johnson K (2014) The evolution of preclinical Alzheimer's disease: implications for prevention trials. Neuron 84:608-622. doi:10.1016/j.neuron.2014.10.038
44. Sperling RA, Aisen PS, Beckett LA, Bennett DA, Craft S, Fagan AM, Iwatsubo T, Jack CR Jr, Kaye J, Montine TJ et al (2011) Toward defining the preclinical stages of Alzheimer's disease: recommendations from the National Institute on Aging-Alzheimer's Association workgroups on diagnostic guidelines for Alzheimer's disease. Alzheimer's Dement J Alzheimer's Assoc 7:280-292. doi:10.1016/j.jalz.2011.03.003

45. Sperling RA, Jack CR Jr, Aisen PS (2011) Testing the right target and right drug at the right stage. Sci Transl Med 3:111 cm133. doi:10.1126/scitranslmed.3002609

46. Sperling RA, Laviolette PS, O'Keefe K, O'Brien J, Rentz DM, Pihlajamaki M, Marshall G, Hyman BT, Selkoe DJ, Hedden $\mathrm{T}$ et al (2009) Amyloid deposition is associated with impaired default network function in older persons without dementia. Neuron 63:178-188. doi:10.1016/j.neuron.2009.07.003

47. Tan MS, Tan L, Jiang T, Zhu XC, Wang HF, Jia CD, Yu JT (2014) Amyloid-beta induces NLRP1-dependent neuronal pyroptosis in models of Alzheimer's disease. Cell Death Dis 5:e1382. doi:10.1038/cddis.2014.348

48. Tong L, Prieto GA, Kramar EA, Smith ED, Cribbs DH, Lynch G, Cotman CW (2012) Brain-derived neurotrophic factor-dependent synaptic plasticity is suppressed by interleukin-1beta via p38 mitogen-activated protein kinase. J Neurosci 32:17714-17724. doi:10.1523/JNEUROSCI.1253-12.2012

49. van Strien ME, Mercier D, Drukarch B, Breve JJ, Poole S, Binnekade R, Bol JG, Blits B, Verhaagen J, van Dam AM (2010) Anti-inflammatory effect by lentiviral-mediated overexpression of IL-10 or IL-1 receptor antagonist in rat glial cells and macrophages. Gene Ther 17:662-671. doi:10.1038/gt.2010.8

50. Volianskis A, Kostner R, Molgaard M, Hass S, Jensen MS (2010) Episodic memory deficits are not related to altered glutamatergic synaptic transmission and plasticity in the CA1 hippocampus of the APPswe/PS1deltaE9-deleted transgenic mice model of ss-amyloidosis. Neurobiol Aging 31:1173-1187. doi:10.1016/j. neurobiolaging.2008.08.005

51. Vos SJ, Xiong C, Visser PJ, Jasielec MS, Hassenstab J, Grant EA, Cairns NJ, Morris JC, Holtzman DM, Fagan AM (2013) Preclinical Alzheimer's disease and its outcome: a longitudinal cohort study. Lancet Neurol 12:957-965. doi:10.1016/ S1474-4422(13)70194-7

52. Wallace W, Bear MF (2004) A morphological correlate of synaptic scaling in visual cortex. J Neurosci 24:6928-6938. doi:10.1523/JNEUROSCI.1110-04.2004

53. Watkins LR, Milligan ED, Maier SF (2001) Glial activation: a driving force for pathological pain. Trends Neurosci 24:450-455

54. Xu T, Yu X, Perlik AJ, Tobin WF, Zweig JA, Tennant K, Jones T, Zuo Y (2009) Rapid formation and selective stabilization of synapses for enduring motor memories. Nature 462:915-919. doi:10.1038/nature08389

55. Xuan AG, Pan XB, Wei P, Ji WD, Zhang WJ, Liu JH, Hong LP, Chen WL, Long DH (2015) Valproic acid alleviates memory deficits and attenuates amyloid-beta deposition in transgenic mouse model of Alzheimer's disease. Mol Neurobiol 51:300-312. doi:10.1007/s12035-014-8751-4

56. Yang G, Pan F, Gan WB (2009) Stably maintained dendritic spines are associated with lifelong memories. Nature 462:920 924. doi:10.1038/nature08577

57. Yuste R, Bonhoeffer $\mathrm{T}$ (2001) Morphological changes in dendritic spines associated with long-term synaptic plasticity. Annu Rev Neurosci 24:1071-1089. doi:10.1146/annurev. neuro.24.1.1071

58. Zou C, Montagna E, Shi Y, Peters F, Blazquez-Llorca L, Shi S, Filser S, Dorostkar MM, Herms J (2015) Intraneuronal APP and extracellular Abeta independently cause dendritic spine pathology in transgenic mouse models of Alzheimer's disease. Acta Neuropathol 129:909-920. doi:10.1007/s00401-015-1421-4 